\title{
Analisis Kontingensi Sistem Transmisi Gpon (Gigabit Passive Optical Network) Area Network Kt2 (Mangga Besar)
}

\author{
Aisyah Tri Astiningsih ${ }^{1, *}$, Baso Maruddani ${ }^{2}$, Arum Setyowati ${ }^{3}$ \\ ${ }^{1}$ Mahasiswa Prodi Pendidikan Teknik Elektronika, Fakultas Teknik - UNJ \\ ${ }^{2,3}$ Dosen Prodi Pendidikan Teknik Elektronika, Fakultas Teknik - UNJ
}

\begin{abstract}
Abstrak. Penelitian dan penulisan skripsi ini bertujuan untuk menganalisis jalur kotingensi mana yang paling baik dalam upaya menyelamatkan data saat jalur tranmisi yang mengalami gangguan, berdasarkan perhitungan dan analisis link budget. Penelitian ini akan mengukur total loss yang terjadi pada core di setiap link yang telah ditentukan. Kemudian akan dilakukan perhitungan total loss dan power link budget menggunakan yang dipengaruhi oleh panjang fiber optik yang digunakan, jenis fiber optik yang digunakan serta jumlah konektor dan jumlah splice yang digunakan. Lalu hasil pengukuran dan perhitungan akan dibandingkan dengan spesifikasi SFP/XFP 10Gb. Berdasarkan pengukuran dan perhitungan yang dilakukan pada ketiga link yang diteliti, link yang paling baik untuk dijadikan jalur kontingensi adalah link KT2 - KT1.
\end{abstract}

Kata kunci : Kontingensi, fiber optik, GPON, power link budget

\begin{abstract}
This research and thesis writing aims to analyze the pathway which contingency is the best in the effort to save data when the transmission line is interrupted, based on link budget calculations and analysis. This study will measure the total loss that occurs in the cores at each predetermined link. Then the total loss and power link budget calculations will be carried out using which is influenced by the length of the optical fiber used, the type of optical fiber used and the number of connectors and the number of splices used. Then the measurement and calculation results will be compared with the 10Gb SFP / XFP specifications. Based on the measurements and calculations made on the three links studied, the best link to be used as a contingency path is the KT2 - KT1 link.
\end{abstract}

Keywords: Contingency, optical fiber, GPON, power link budget

\section{Pendahuluan}

Perkembangan dunia teknologi saat ini sangat pesat seiring dengan peningkatan kebutuhan layanan yang cepat dan efisien serta berkapasitas yang besar. Begitu juga dengan sistem komunikasi, mulai dari komunikasi suara hingga komunikasi data. Semakin berkembangnya dunia teknologi informasi dan komunikasi atau Information and Communication Technology (ICT) semain banyak pula media transmisi yang ditawarkan. Sistem telekomunikasi dan informasi membutuhkan jaringan yang handal dan bandwitdth yang besar serta sistem proteksi yang mampu mengamankan kelangsungan pengiriman informasi dari sumber (source) ke tujuan (destination). Media transmisi yang digunakan untuk mengirimkan informasi tersebut salah satunya adalah fibre optic. Perangkat yang dioperasikan untuk mengirimkan informasi tersebut diantaranya berbasis GPON (Gigabit Passive Optical Network).Kontingensi merupakan strategi yang dibangun untuk menjaga kontiyuitas traffic guna menjaga sistem komunikasi agar dilewatkan secara terus menerus tanpa mengalami traffic affecting (terputusnya hubungan). Strategi kontingensi didisain semaksimal mungkin dapat menyelamatkan trafik yang terganggu dan tindakan normalisasi sebanyak-banyaknya, jika tidak memungkinkan semua trafic dapat diselamatkan, perlu dibuat skala prioritas link atau sistem mana saja yang akan diprioritaskan.Perangkat existing yang ada saat ini sudah menggunakan sistem proteksi yang handal namun dibeberapa ruas tertentu belum memiliki atau menggunakan sistem switch over atau perpindahan kejalur kontingensi saat terjadi gangguan. Begitu juga dengan perangkat GPON pada STO KT2 (Mangga Besar) yang belum mempunyai jalur kontingensi. Hal itu dapat mengakibatkan kerugian bagi pelanggan maupun perusahaan. Oleh karena itu, 44 penentuan jalur kontingensi pada area network KT2 (Mangga Besar) sangat dibutuhkan. 


\section{Metodologi}

Pada penelitian kali ini peneliti menggunakan pendekatan kuantitatif. Dimana proses penelitian dimulai dengan masalah yang dihadapi. Permasalahan tersebut dikaji secara teoritis, dicari dasardasar rasionalitasnya. Kemudian dilakukan data empiris, untuk diambil kesimpulannya. Gambar 1.1 akan menampilkan topologi area network kota, sebagai berikut:

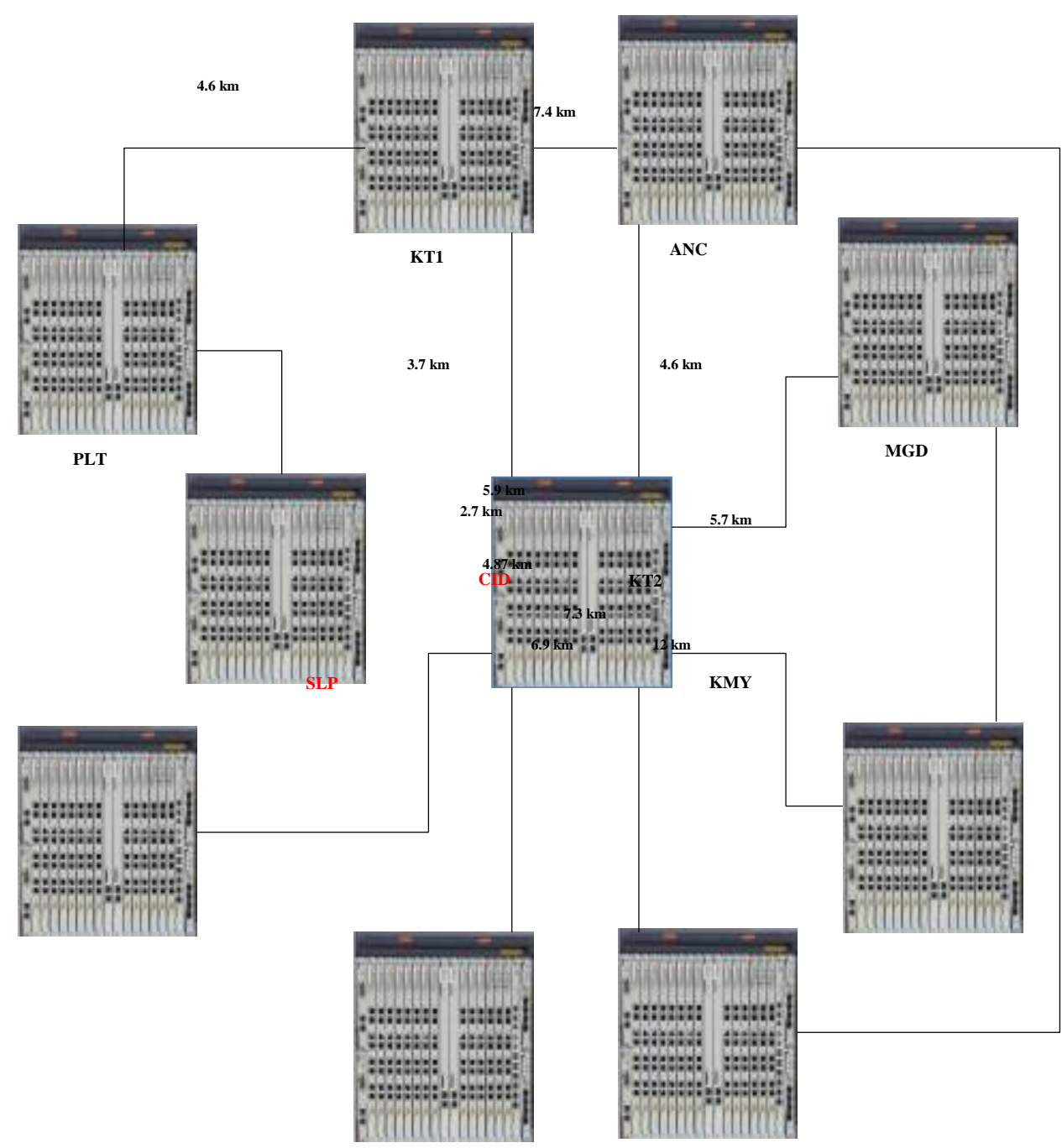

\section{CPP STR}

Gambar 1. Topologi area network kota

Keterangan nama dengan warna hitam menunjukan Area Network Jakarta Utara. Sedangkan keterangan nama dengan warna merah menunjukan Area Network Jakarta Barat.

Dalam penelitian ini akan menganalisis kontingensi GPON pada STO KT2. Dari 9 link yang tercabtum diatas, penulis akan menggunakan 3 link yang akan diteliti, yaitu :

1. KT2 - KT1, dengan jarak $3.70 \mathrm{~km}$.

2. KT2 - ANC, dengan jarak $4.60 \mathrm{~km}$.

3. KT2 - MGD, dengan jarak $5.90 \mathrm{~km}$.

\section{Hasil}

\subsection{Hasil Pengukuran}

Pengukuran dilakukan di setiap STO (Sentral Telepon Otomat) yang bersangkutan. Pengukuran dilakukan untuk mengetahui loss yang terdapat di beberapa core disetiap STO. Pengukuran dilakukan dengan menggunakan Optical Power Mater (OPM) dan Handle Laser Sources (HLS). 
Tabel 1. Hasil Pengukuran KT2 - KT1

\begin{tabular}{ccccc}
\hline & \multicolumn{2}{c}{ STO } & & $\begin{array}{c}\text { Loss } \\
\text { No }\end{array}$ \\
\cline { 2 - 3 } & KT2 (dB) & KT1 (dB) & Core & $\begin{array}{c}\text { Fiber Optik } \\
\text { (dB) }\end{array}$ \\
\hline 1 & 1.35 & 0.71 & 31 & 1.03 \\
2 & 1.35 & 0.38 & 32 & 0.86 \\
3 & 1.32 & 0.37 & 33 & 0.84 \\
4 & 2.11 & 0.32 & 34 & 1.21 \\
5 & 2.12 & 0.59 & 35 & 1.35 \\
\hline \multicolumn{5}{c}{ Rata - Rata Total Loss } \\
\hline
\end{tabular}

Sumber: Data Penelitian Penulis

pada tabel 1 dapat diketahui bahwa pada core yang diuji semuanya dalam kondisi baik, karena cahaya laser yang dikirim HLS (Handle Light Source) dapat terbaca OPM (Optical Power Meter). Dari beberapa total loss yang dihitung didapatkan rata-rata total loss yaitu sebesar $1.06 \mathrm{~dB}$.

Tabel 2. Hasil Perhitungan KT2 - ANC

\begin{tabular}{|c|c|c|c|c|}
\hline \multirow{2}{*}{ No } & \multicolumn{2}{|c|}{ STO } & \multirow{2}{*}{ Core } & \multirow{2}{*}{$\begin{array}{c}\text { Loss } \\
\text { Fiber Optik (dB) }\end{array}$} \\
\hline & KT2 (dB) & $\mathrm{ANC}(\mathrm{dB})$ & & \\
\hline 1 & 2.43 & 0.07 & 45 & 1.25 \\
\hline 2 & 2.31 & 0.59 & 46 & 1.45 \\
\hline 3 & 3.52 & 0.71 & 47 & 2.11 \\
\hline 4 & 3.01 & 0.60 & 48 & 1.81 \\
\hline 5 & 2.90 & 0.58 & 49 & 1.74 \\
\hline \multicolumn{4}{|c|}{ Rata - Rata Total Loss } & 1.67 \\
\hline
\end{tabular}

Sumber: Data Penelitian Penulis

Berdasarkan hasil pengukuran pada tabel 2 dapat diketahui bahwa pada core yang diuji semuanya dalam kondisi baik, karena cahaya laser yang dikirim HLS (Handle Light Source) dapat terbaca OPM (Optical Power Meter). Dari beberapa total loss yang dihitung didapatkan rata- rata total loss yaitu sebesar $1.67 \mathrm{~dB}$. 
Tabel 3. Hasil Perhitungan KT2 dan MGD

\begin{tabular}{|c|c|c|c|c|}
\hline \multirow{2}{*}{ No } & \multicolumn{2}{|c|}{ STO } & \multirow{2}{*}{ Core } & \multirow{2}{*}{$\begin{array}{c}\text { Loss } \\
\text { Fiber Optik (dB) }\end{array}$} \\
\hline & KT2 (dB) & MGD (dB) & & \\
\hline 1 & 2.70 & 0.55 & 7 & 1.62 \\
\hline 2 & 2.74 & 0.50 & 8 & 1.62 \\
\hline 3 & 1.13 & 0.59 & 9 & 0.86 \\
\hline 4 & 3.25 & 0.65 & 10 & 1.95 \\
\hline 5 & 2.86 & 0.57 & 11 & 1.71 \\
\hline \multicolumn{4}{|c|}{ Rata - Rata Total Loss } & 1.55 \\
\hline
\end{tabular}

Sumber: Data Penelitian Penulis

Berdasarkan hasil pengukuran pada tabel 3 dapat diketahui bahwa pada core yang diuji semuanya dalam kondisi baik, karena cahaya laser yang dikirim HLS (Handle Light Source) dapat terbaca OPM (Optical Power Meter). Dari beberapa total loss yang dihitung didapatkan rata- rata total loss yaitu sebesar $1.55 \mathrm{~dB}$.

\subsection{Hasil Perhitungan}

\section{A. Perhitungan Splice}

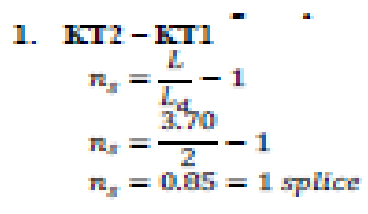

2. KT2-ANC

$$
\begin{aligned}
& n_{x}=\frac{L}{L_{4}}-1 \\
& n_{x}=\frac{4.50}{2}-1 \\
& n_{n}=1.30=2 \text { splice }
\end{aligned}
$$

3. $\mathrm{KT} 2-\mathrm{M} G \mathrm{D}$

$$
\begin{aligned}
& n_{n}=\frac{L}{L_{d}}-1 \\
& n_{n}=\frac{2.90}{2}-1 \\
& n_{n}=1.95=2 \text { splice }
\end{aligned}
$$

4.2.2 Perkirungan Loos

1. $\mathrm{KT} 2-\mathrm{KT} 1$

$\Sigma$ Lass $=\left(L_{L} L_{s}\right)+\left(n_{c} \cdot L_{c}\right)+\left(n_{x} \cdot L_{x}\right)$

$=(0.35 \mathrm{~dB} / \mathrm{km} \times 3.70 \mathrm{~km})+$

$$
\begin{aligned}
& (0.75 \mathrm{~dB} \times 2)+(0.01 \mathrm{~dB} \times 1) \\
= & 1.295+1.50+0.01 \\
= & 2.81 \mathrm{~dB} \\
2 . \mathrm{KT} 2 & -\mathrm{ANC} \\
\sum \text { Loss }= & \left(L . L_{f}\right)+\left(n_{c}-L_{c}\right)+\left(n_{r}, L_{2}\right) \\
= & (0.35 \mathrm{~dB} / \mathrm{km} \times 4.60 \mathrm{~km})+ \\
& (0.75 \mathrm{~dB} \times 2)+(0.01 \mathrm{~dB} \times 2) \\
= & 1.61+1.50+0.02 \\
= & 3.13 \mathrm{~dB}
\end{aligned}
$$

3. $\mathrm{KT} 2-\mathrm{MGD}$

$$
\begin{aligned}
\sum \text { Loss }= & \left(L_{1} L_{f}\right)+\left(n_{c} \cdot L_{c}\right)+\left(n_{y} \cdot L_{2}\right) \\
= & (0.35 \mathrm{~dB} \mathrm{~km} \times 5.90 \mathrm{~km})+ \\
& (0.75 \mathrm{~dB} \times 2)+(0.01 \mathrm{~dB} \times 2) \\
= & 2.065+1.50+0.02 \\
= & 3.58 \mathrm{~dB}
\end{aligned}
$$

\section{B. Perhitungan PRx}

Perhitungan PRx menggunakan persamaan 2.3, dengan besar margin 8 dB. Berikut adalah perhitungan PRx di masing-masing link:

\section{KT2 - KT1}


Tabel 4 Hasil Perhitungan KT2 - KT1

\begin{tabular}{|c|c|c|c|c|}
\hline $\mathrm{N}_{0}$ & $\begin{array}{c}\text { PTX } \\
\text { (dBm) }\end{array}$ & Perhitengan & $\begin{array}{c}\text { PRx } \\
\text { (dBm) }\end{array}$ & Keterangan \\
\hline 1 & -8 & $-8-2.81-8$ & -18.81 & Tidak Mememhi Spesifiknsi \\
\hline 2 & -7 & $-7-2.81-8$ & -17.31 & Tidak Mememhi Speaifikai \\
\hline 3 & -6 & $-6-2.81-8$ & -16.81 & Tidak Memenhi Spesifikani \\
\hline 4 & -5 & $-5-2.01-0$ & -15.81 & Tidak Metmemhi Spesifikai \\
\hline 5 & -4 & $-4-2.81-8$ & -14.81 & Tidak Mememhi Spesifikasi \\
\hline 6 & -3 & $-3-2.81-8$ & -13.81 & Memenuhi Spesifkasi \\
\hline$\gamma$ & -2 & $-2-2.81-8$ & -12.31 & Mennenuh Spesifmi \\
\hline 8 & -1 & $-1-2.81-8$ & -11.81 & Meneming Spesifnsi \\
\hline 9 & 0.5 & $0.5-2.81-8$ & -10.31 & Mennenuhi Spesithai \\
\hline
\end{tabular}

Dari hasil perhitungan pada tabel 4 dapat diketahui bahwa link KT2 - KT1 dapat memenuhi spesifikasi, dimana dengan nilai Px maksimum sebesar $0.5 \mathrm{dBm}$, Rx yang dihasilkan sebesar $10.31 \mathrm{dBm}$

Tabel 5 Hasil Perhitungan KT2 - ANC

\begin{tabular}{|c|c|c|c|c|}
\hline No & $\begin{array}{c}P T x \\
(\mathrm{dBm})\end{array}$ & Perthitangal & $\begin{array}{c}P R x \\
(d B m)\end{array}$ & Keterangau \\
\hline 1 & -8 & $-8-3.13-8$ & -19.13 & Tidak Mememuhi Spesifikasi \\
\hline 2 & -7 & $-7-3.13-8$ & -18.13 & Tidak Mememxhi Spesifiknsi \\
\hline 3 & -6 & $-6-3.13-8$ & -17.13 & Tidak Mememxhi Spesifikasi \\
\hline 4 & -5 & $-5-3.13-8$ & -16.13 & Tidak Mememuhi Spesifiknsi \\
\hline 5 & -4 & $-4-3.13-8$ & -15.13 & Tidak Mememubi Spesifikmai \\
\hline 6 & -3 & $-3-3.13-8$ & -14.13 & Memennhi Spesifkai \\
\hline 7 & -2 & $-2-3.13-8$ & -13.13 & Memenuhi Spesifkasi \\
\hline 8 & -1 & $-1-3.13-8$ & -1213 & Memenuhi 5 pesifkasi \\
\hline 9 & 0.5 & $0.5-3.13-8$ & -10.63 & Mememuhi 5pesifkasi \\
\hline
\end{tabular}

Dari hasil perhitungan pada tabel 5 dapat diketahui bahwa link KT2 - ANC dapat memenuhi spesifikasi, dimana dengan nilai Px maksimum sebesar $0.5 \mathrm{dBm}$, Rx yang dihasilkan sebesar - 10.63 $\mathrm{dBm}$.

\section{KT2 - MGD}

Tabel 6 Hasil Perhitungan KT2 - MGD

\begin{tabular}{|c|c|c|c|c|}
\hline No & $\begin{array}{c}P T X \\
(\mathrm{dBm})\end{array}$ & Porkitumgan & $\begin{array}{c}P R x \\
(\mathrm{~d} \mathrm{Bm})\end{array}$ & Keteraagan \\
\hline 1 & 8 & $-8=3.58=8$ & -19.58 & Thalk Mememini Spesifikasi \\
\hline 2 & -7 & $-7-3.58-8$ & -18.50 & Tidas Memenuti Spesifîkasi \\
\hline 3 & -6 & $-6-3.58-8$ & -17.58 & Tidak Memenuli Sperifikari \\
\hline 4 & -5 & $-5-3.58-8$ & -16.58 & Tidat Memenuhi Spesifikni \\
\hline 5 & -4 & $-4-3.58-8$ & -15.58 & Tidak Memenuti Spesifikssi \\
\hline 7 & -3 & $-3-3.58-8$ & -14.58 & Todak Menuesuhi Spesifllasi \\
\hline 8 & -2 & $-2-3.58-8$ & -13.58 & Manemhi Spesilkasi \\
\hline 9 & -1 & $-1-3.58-8$ & -12.58 & Memenuli Spesilkasi \\
\hline 10 & 0.5 & $0.5-3.58-8$ & -11.58 & Mamemhi Spesikasi \\
\hline
\end{tabular}

Dari hasil perhitungan pada tabel 6 dapat diketahui bahwa link KT2 - MGD dapat memenuhi 
spesifikasi dimana dengan nilai Px maksimum sebesar $0.5 \mathrm{dBm}$, Rx yang dihasilkan sebesar -11.58 $\mathrm{dBm}$.

\subsection{Hasil Analisis}

Tabel 7 Hasil Perhitungan Total Loss

\begin{tabular}{cccccc}
\hline No & Link & Jarat & Junlah & Jumlah & Los \\
& & (Km) & Konalotor & Sumbunga & (dB) \\
\hline 1 & KT2-KT1 & 3.70 & 2 & 1 & 2.51 \\
2 & KT - ANC & 4.60 & 2 & 2 & 3.13 \\
3 & KT2-MCD & 590 & 2 & 2 & 3.58 \\
\hline
\end{tabular}

Berdasarkan hasil tabel 7, jika diamati dengan mengacu pada spesifikasi fiber optik single-mode 1330 yang tertera pada tabel 1, dan rumus pada persamaan 2.3, dapat diketahui bahwa variabel yang paling banyak menghasilkan loss adalah jarak dan jumlah konektor. Namun karena jumlah konektor dan jarak transmisi tidak dapat dikurangi, faktor yang dapat diubah untuk mengurangi total loss adalah redaman per kilometer. Dimana itu dapat dilakukan dalam menentukan jenis fiber optik yang digunakan.

Berdasarkan persamaan 2.4, total loss menjadi faktor yang mempengaruhi besar daya yang diterima receiver. Sehingga besarnya total loss harus diperhatikan untuk mendapat daya receiver yang ditentukan agar dapat meminimalis besar daya yang dikirim transmitter. Berikut adalah grafik perbandingan antara hasil pengukuran dan hasil pengukuran total loss yang terjadi di masing-masing link yang diteliti:

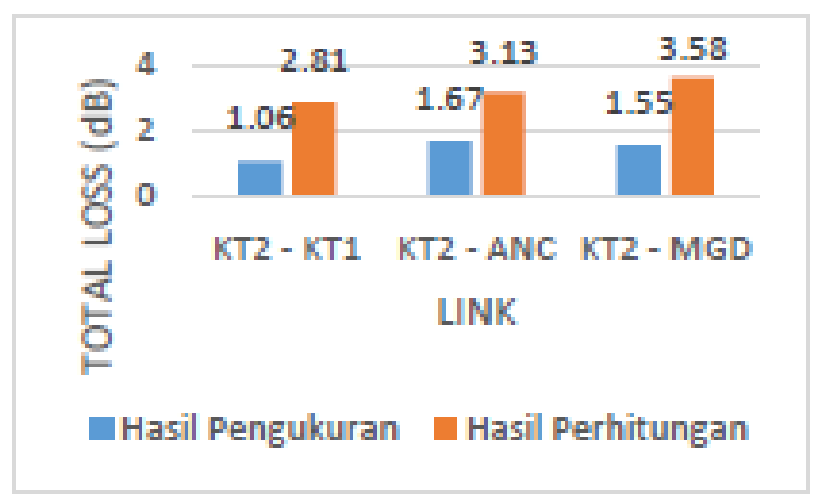

Gambar 2 Perbandingan Total Loss

Berdasarkan grafik 2 terlihat bahwa pengukuran rata-rata total loss yang paling kecil adalah pada link KT2 - KT1, yaitu $1.06 \mathrm{~dB}$. Semakin rendah redaman (loss) yang terdapat pada jalur transmisi, maka akan semakin baik pula kondisi jalur tersebut. Sehingga dapat dikatakan bahwa dari ketiga link yang di amati, menurut hasil pengukuran link yang paling baik untuk dijadikan jalur kontingensi adalah KT2 - KT1. Hal tersebut berbanding lurus dengan hasil perhitungan dimana total loss yang paling kecil terdapat pada link KT2 - KT1 yaitu sebesar $2.81 \mathrm{~dB}$.

Berdasarkan spesifikasi SPF yang telah dilampirkan pada tabel 1, minimum Rx yang telah ditentukan adalah -14.4 dBm. Dengan kata lain jika Rx kurang dari $-14.4 \mathrm{dBm}$, kondisi tersebut tidak dapat digunakan sebagai jalur kontingensi. Pada hasil perhitungan didapatkan bahwa ketiga link yang diamati dapat memenuhi spesifikasi yang ditentukan.

Untuk menentukan link yang paling baik dari dapat dilakukan melihat besar Rx menggunakan Px maksimal berdasarkan spesifikasi SPF/XPF module $10 \mathrm{~Gb}$ sebesar $0.5 \mathrm{dBm}$, Rx yang didapat pada link KT2 - KT1 sebesar -10.31 dBm, pada link KT2 - ANC sebesar - $10.63 \mathrm{dBm}$ dan pada link KT2 - MGD sebesar -11.58 dBm. Sehingga link yang paling baik dijadikan jalur kontingensi berdasarkan perhitungan adalah link KT2 - KT1. 


\section{Kesimpulan}

Berdasarkan hasil analisis dari proses pengukuran dan perhitungan yang dilakukan, maka dapat ditarik kesimpulan, yaitu:

1. Total loss menjadi faktor yang menentukan besar daya pada receiver, untuk meminimalis besar daya input yang diberikan. Ada beberapa variabel yang menjadi penentu besar total loss yaitu jarak, jumlah konektor, dan jumlah sambungan (splice). Dari variabel tersebut, variabel yang paling banyak menghasilkan loss adalah redaman konektor dan redaman per km jarak. Namun karena jumlah konektor dan jarak media transmisi tidak dapat diubah, maka yang perlu dipertimbangkan dalam perancangan sistem transmisi adalah pemilihan jenis kabel, karena pemilihan jenis kabel akan memberikan besar redaman yang berbeda.

2. Berdasarkan pengukuran dan perhitungan yang dilakukan pada ketiga link yang diteliti, link yang paling baik untuk dijadikan jalur kontingensi adalah link KT2 - KT1. Dimana berdasarkan hasil pengukuran dan perhitungan, total loss yang paling kecil adalah pada link KT2 - KT1 dengan nilai Rx power yang tidak melewati spesifikasi yang ditentukan yaitu -14.4 $\mathrm{dBm}$.

\section{DAFTAR PUSTAKA}

1. Abral, Minal. (2016). Analisis Redaman Pada Jaringan FTTH (Fiber To The Home) Dengan Teknologi GPON (Gigabit Passive Optical Network) di PT MNC KabelMediacom. Jakarta

2. Ali. (2013). Apa Itu SFP Tranceiver. http://www.jaringan- komputer.cv-sysneta.com /apa- itu-sfptransceiver. Diakses 10 Januari 2017.

3. [Anonim].(2010).Kontingensi Transmisi. Jakarta: PT. Telekomunikasi Indonesia.

4. Crisp, John \& Elliott, Barry. (2006).Serat Optik: Sebuah Pengantar. Jakarta: Erlangga.

5. Harahap, Sofyan Syafri.(2004). Analisi Krisis atas Laporan Keuangan. Jakarta: Rajawali Pers.

6. Iswari, Deswinta. (2015). Evaluasi Perancangan Jaringan Serat Optik Berbasis GPON (Gigabit Passive Optical Network) Dari STO Penggilingan Sampai SMK Jakarta Timur 2. .[skripsi]. Jakarta: Fakultas Teknik. Universitas Negeri Jakarta.

7. Keiser, Gerd. (2000). Optical Fiber Communication. Singapura. Edisi Ketiga: McGraw Hill.

8. Kristanto, Endi Dwi. (2012). Fiber Optik Atas Tanah. Yogyakarta: Ilmu computer.

9. Palais, Joseph. (1998). Fiber Optic Communication, Fourth Edition. USA: Prentice Hall.

10. Santoso, Gempur. (2005). Metodologi Penelitian Kuantitatif dan Kualitatif. Jakarta: Prestasi Pustaka.

11. Solekan.(2009). Sistem Telekomunikasi. Bandung: Politeknik Telkom Bandun 